\title{
Formação e desenvolvimento de acervos em biblioteca escolar como recurso para promover a competência informacional infantil: importância, desafios e perspectivas
}

Formation and development of school library collections as a resource to promote children's informational competence: importance, challenges and perspectives

Niliane Cunha de Aguiar Doutora em Ciência da Informação pela Universidade Federal de Minas Gerais - UFMG, Brasil. Professora Adjunta da Universidade Federal de Sergipe - UFS, Brasil.

E-mail: nilianeaguiar@yahoo.com.br

\author{
Telma de Carvalho \\ Doutora em Ciência da Informação pela Universidade de São Paulo - USP, Brasil. \\ Professora Doutora do curso de Biblioteconomia e Documentação da Universidade Federal de Sergipe - UFS, \\ Brasil. \\ E-mail: telmac@academico.ufs.br
}

\begin{abstract}
Resumo
Este estudo, de caráter bibliográfico, apresenta reflexões sobre o desenvolvimento de coleções em bibliotecas escolares, embasadas nos princípios que regem esse processo, a fim de demonstrar a importância de sua adequação a essa tipologia de unidade de informação. Tem por objetivo destacar a importância da formação de coleções em bibliotecas escolares a partir da seleção e aquisição de acervos específicos para as necessidades informacionais de crianças com vistas à promoção da competência informacional infantil dos alunos. Conclui-se que é papel do bibliotecário escolar a adoção de medidas que visem um conhecimento aprofundado a respeito do público infantil para assim prover os recursos, produtos e serviços informacionais adequados para este público.
\end{abstract}

Palavras-chave: Biblioteca Escolar. Formação e Desenvolvimento de Coleções. Competência Informacional Infantil.

\begin{abstract}
This bibliographical study presents reflections on the development of collections in school libraries, based on the principles that govern this process, in order to demonstrate the importance of its adequacy to this typology of information unit. Its purpose is to highlight the importance of formation of collections in school libraries from the selection and acquisition of specific collections for the informational needs of children, with a view to promoting the children's informational competence of students. It is concluded that it is the role of the school librarian to adopt measures aimed at in-depth knowledge of the child audience in order to provide the appropriate information resources, products and services for this audience.
\end{abstract}

Keywords: School Library. Formation and Development of Collections. Children's Informational Competence. 


\section{Introdução}

Ao entendermos que é papel da família, da escola e da sociedade, oferecer às crianças as informações que precisam para que melhor possam desenvolver-se na compreensão do mundo em que vivem, observamos também que, para que isso aconteça, a criança deve ser vista inicialmente como uma usuária potencial de informação.

A partir de tal concepção, é possível admitir que o acervo da biblioteca escolar, deve ser analisado em concordância com os preceitos de Martínez-Silveira e Oddone (2007), ao afirmarem que cada grupo de usuário possui particularidades em relação à necessidade informacional, e que assim sendo, o público infantil também possui características próprias para os quais, no entendimento de Fialho e Andrade (2007), a biblioteca escolar e seus serviços devem ser considerados partes fundamentais para o desenvolvimento da competência informacional em crianças e adolescentes.

Desse modo, conforme afirma Pieruccini (2004, p. 30), a biblioteca para crianças e jovens

é um dispositivo complexo, constituído por elementos heterogêneos: arquitetura e ambiente, técnicas e tecnologias, processos e produtos, regras e regulamentos, conteúdos materiais e imateriais, responsáveis por sobrepor significados aos significados por ela guardados, constituindo-se elementos de sua natureza.

Tal realidade conduz ao seguinte questionamento: qual a importância do desenvolvimento de coleções em bibliotecas escolares em relação à promoção da competência informacional infantil?

Para respondê-lo, este trabalho tem como objetivo geral: identificar, pela literatura, como o desenvolvimento de coleções em bibliotecas escolares pode contribuir para a efetivação da competência informacional infantil e, por objetivos específicos: 1) apresentar a importância da elaboração de uma política de desenvolvimento de coleções nestes ambientes; 2) tecer comentários sobre a atuação efetiva do bibliotecário na biblioteca escolar, inclusive nas comissões de seleção para a composição do acervo e 3) comentar sobre a relação do acervo para a formação da competência informacional .

A metodologia utilizada para alcançar este objetivo parte do método científico dialético, utilizando a interlocução entre as teorias e práticas apresentadas por diversos autores que debatem o tema, a exemplo dos autores que serão apresentados no referencial teórico deste estudo. Do ponto de vista da sua natureza, esta pesquisa é básica, também conhecida 
Formação e desenvolvimento de acervos em biblioteca escolar como recurso para promover a competência informacional infantil: importância, desafios e perspectivas

como pura, uma vez que o resultado de suas reflexões destinam-se a aumentar a base de conhecimento científico sobre a temática proposta, podendo abastecer teoricamente, seu objetivo que é a geração de novos conhecimentos que sejam úteis para o avanço científico, sem condicionar uma aplicação prática prevista (SILVA; MENEZES, 2005). Do ponto de vista da forma de abordagem, este estudo é qualitativo e do ponto de vista dos seus objetivos é uma pesquisa descritiva pois pretende descrever, analisar e interpretar o objeto de estudo (TAQUETTE; BORGES, 2020). Os procedimentos técnicos da pesquisa foram realizados através de pesquisa bibliográfica, tendo como instrumento a revisão de literatura. E a interpretação e a análise dos resultados será embasada pela análise das narrativas apresentadas.

Nesta seção introdutória é importante ressaltar, portanto, em concordância com Campello et al. (2009) que embora os alunos tragam para a escola uma bagagem de conhecimento que não deve ser desprezada, por vezes adquirida em contato com os meios de comunicação, a escola é o espaço por excelência para estender e aprofundar o contato com os mais variados recursos informacionais atualmente disponíveis, os quais se tornam cada vez mais indispensáveis para viver e conviver na sociedade da informação.

Desse modo, sabe-se que diversas mudanças têm sido propostas para adequar os currículos escolares aos novos parâmetros exigidos pela atual sociedade. Tal mudança pode ser comprovada pelo livro de introdução aos Parâmetros Curriculares Nacionais (PCN), ao recomendar que os alunos de $1^{\mathrm{a}}$ à $4^{\mathrm{a}}$ do ensino fundamental sejam capazes de "saber utilizar fontes de informação e recursos tecnológicos para adquirir e construir conhecimentos" (BRASIL, 1997, p. 69). A Base Nacional Comum Curricular (BNCC) também enfatiza a utilização dos "conhecimentos historicamente construídos sobre o mundo físico, social, cultural e digital" (BRASIL, 2017, p. 7).

Ressalta-se assim, a importância da integração biblioteca/escola, uma vez que os maiores usuários da biblioteca são os alunos e o estreitamento desta relação favorece o bom desempenho de todos. Ao se conhecer melhor o papel da biblioteca na escola, seu uso será melhorado e beneficiará o ensino/aprendizagem e a educação dos estudantes, na oferta de atividades conjuntas e de melhores serviços, conforme salientam os princípios e diretrizes da biblioteca pública (FUNDAÇÃO BIBLIOTECA NACIONAL, 2010).

Acredita-se, portanto, que o bibliotecário que está inserido no espaço escolar deve participar, ativamente, dos planejamentos dos projetos políticos pedagógicos uma vez que tem 
a competência necessária para atuar no desenvolvimento de coleções de qualidade, contribuindo para a formação de um acervo que não apenas atenda às demandas informacionais de sua comunidade, mas que seja atrativo e estimulante para o seu público (GARCEZ, 2007), merecendo um destaque quando se trata do público infantojuvenil.

A segunda seção apresenta os conceitos e práticas sobre a formação e desenvolvimento de coleções em bibliotecas escolares; a terceira relaciona a qualidade do acervo da biblioteca escolar com a promoção da competência informacional infantil e a quarta e última descreve as considerações finais proporcionadas pelas análises realizadas.

\section{Formação e desenvolvimento de acervos em bibliotecas escolares}

Entende-se por acervo, em consonância com Haum (2009, p. 9) "a reunião de todos os documentos que, juntos, formam uma coleção". A mesma autora ainda frisa que para a constituição de coleções, em qualquer unidade de informação, estes documentos devem, além de serem fontes de informação, comungar, necessariamente, das finalidades e funções para as quais tais unidades foram criadas.

O acervo pode ser considerado como o ponto mais atrativo da biblioteca, pois de acordo com Garcez (2007, p. 32), é ele que "serve para cativar e estimular, nos usuários, o interesse pela sua utilização, por essa razão é necessária a sua diversificação". Nessa perspectiva, acredita-se que os responsáveis pela biblioteca escolar precisam constantemente avaliar a qualidade do acervo disponibilizado aos seus usuários, levando-se em conta as características da instituição. Além disso, a avaliação do acervo é de fundamental importância, pois é através dela que são obtidos dados seguros em relação à adequação e utilização do acervo pelo público. Conforme enfatizam Dias e Pires (2003, p. 49), "estabelecer padrões com bases em medidas e números para avaliar coleções é uma das funções do setor que cuida da formação e do desenvolvimento de coleções". Nesse sentido, as coleções podem ser avaliadas por suas características qualitativas e/ou quantitativas. Alguns modelos preconizados pela literatura para a avaliação do acervo são considerados, como o Modelo Conspectus que possibilita conhecer a coleção por assunto, a partir de um sistema de classificação, servindo de apoio para a elaboração de políticas de desenvolvimento de coleções (CARIBÉ, 2014). 
Formação e desenvolvimento de acervos em biblioteca escolar como recurso para promover a competência informacional infantil: importância, desafios e perspectivas

Também de acordo com o Manifesto da Federação Internacional de Associações de Bibliotecários e Instituições (IFLA) juntamente com a Organização das Nações Unidas para Educação, Ciência e Cultura (UNESCO) (IFLA; UNESCO, 1999, p. 2-3) o acervo da biblioteca escolar merece destaque, e por esse motivo, recomenda-se dentre outras coisas, que a mesma deve

prover acesso em nível local, regional, nacional e global aos recursos existentes e às oportunidades que expõem os aprendizes a diversas ideias, experiências e opiniões e precisa desenvolver e manter nas crianças o hábito e o prazer da leitura e da aprendizagem, bem como o uso dos recursos da biblioteca ao longo da vida.

Porém, conforme o Projeto Mobilizador elaborado pelo Conselho Federal de Biblioteconomia (CONSELHO FEDERAL DE BIBLIOTECONOMIA, 2008, p. 7) é importante enfatizar que

não é só necessário disponibilizar acervos, mas, acima de tudo, viabilizar o acervo ao conjunto dos saberes que este acervo possui para que, a partir do contexto da escola, do seu projeto pedagógico e da cultura geral que compõe tal conjunto de saberes, fundamentam e dão sentido ao modo de vida e à existência de cada membro da comunidade escolar.

Fonseca (2007) afirma que a biblioteca não pode ser um aglomerado de livros e revistas amontoados pelo mero acaso, sem qualquer tipo de planejamento e seleção. Da mesma forma, Paiva e Berenblum (2009, p. 185) após realizarem a avaliação diagnóstica do Programa Nacional de Biblioteca da Escola (PNBE), relataram que

muitas bibliotecas se confundiam com depósitos de livros amontoados sem nenhum critério nem organização e, muitas vezes, se encontraram livros empacotados em suas embalagens originais. Outras se reduziam a 'armariotecas'.

As autoras ainda destacaram a falta de registros dos materiais da biblioteca, impossibilitando a criação de um catálogo capaz de apresentar de forma eficiente à comunidade escolar as obras que dispõem.

Levando-se em conta o pensamento desses autores, reforça-se a noção de que é imprescindível a elaboração de um documento que defina a política para o desenvolvimento de coleções, respeitando o objetivo e a finalidade social da unidade de informação.

Diante desse contexto, Silva (2011, p. 22) afirma que uma política de desenvolvimento de coleções adequada à biblioteca escolar se constitui em ferramenta importante para propiciar informações de qualidade e atualizadas, características fundamentais para o exercício pleno de sua missão. 
Porém, Barreto (2008) mostra que, infelizmente, percebe-se num contexto geral, uma falta de integração entre a biblioteca e o projeto político-pedagógico da escola, que prejudica o desenvolvimento do potencial educativo da biblioteca escolar, comprometendo também a qualidade do acervo.

Em meio a tal realidade, é emergente considerar a sistematização de políticas de desenvolvimento e formação de acervos como uma atividade fundamental para a universalização das bibliotecas escolares instituída pela lei 12.244 de 24 de maio de 2010 (BRASIL, 2010), levando-se em conta a previsão de que as escolas devam possuir bibliotecas.

O termo desenvolvimento de coleções, conforme Vergueiro (1993, p. 14), é uma expressão biblioteconômica que ganhou impulso a partir da década de sessenta, quando nos Estados Unidos, apesar dos fortes investimentos em construções de prédios para alocação das coleções, percebeu-se que não era racional adquirir tudo o que era produzido, pois com o crescimento exponencial da informação as coleções passaram a ser um produto resultante das necessidades institucionais e, consequentemente, de seus usuários.

Após o que Vergueiro (1989) denominou de “boom” do desenvolvimento de coleções, o interesse pela área arrefeceu, em detrimento da necessidade de se concentrar esforços técnicos para implementar a automação das bibliotecas e sistemas de informação com dedicação ao processamento técnico das informações, e tal forma de pensamento, infelizmente ainda se mantém em algumas bibliotecas, dificultando a formação qualitativa de seus acervos, visto que há maior preocupação com os sistemas de automação utilizados do que propriamente com o desenvolvimento de um acervo de qualidade.

Ainda de acordo com Vergueiro (1997, p. 102), refletir sobre o desenvolvimento do acervo, não significa se basear apenas em critérios de custo-benefício, mas, sobretudo, em políticas de seleção, observando-se “desde as características inerentes ao campo de conhecimento no qual a seleção ocorre, às particularidades específicas dos clientes e do próprio ambiente no qual os serviços de informação se localizam". Isso porque os materiais que comporão o acervo da biblioteca têm estrito relacionamento com as necessidades do público atendido.

Neste estudo, compreende-se, portanto, que a formação e o desenvolvimento de coleções deve ser realizada a partir de um planejamento que se consolida de forma documental numa política de desenvolvimento de coleções. Esse planejamento é constituído 
Formação e desenvolvimento de acervos em biblioteca escolar como recurso para promover a competência informacional infantil: importância, desafios e perspectivas

por etapas que formam o processo de desenvolvimento de coleções, e cada uma dessas etapas possuem as suas especificidades: a política de seleção, a política de aquisição, a política de avaliação e a política de descarte. A reunião de todas essas políticas forma a política de formação e desenvolvimento de coleções.

A seleção, conforme aponta Vergueiro (2010) é uma importante etapa do processo de desenvolvimento de coleções, pois auxilia na escolha do item que, neste caso, fará parte do acervo para atender as necessidades da comunidade escolar. Uma vez que há um grande número de publicações, a adoção de critérios, estipulados em comum acordo com representantes da comissão de seleção e também baseados na literatura existente sobre o assunto, devem ser observados, tais como: adequação ao currículo, atualidade, autoridade, custo, entre outros. A comissão de seleção tem caráter deliberativo quando ela é composta também por professores e outros membros da comunidade e embora isso pareça "representar uma limitação à autoridade/autonomia do profissional [bibliotecário], seus aspectos positivos devem ser explorados ao máximo" (VERGUEIRO, 2010, p. 59 apud WEITZEL, 2012, p. 185). Para Weitzel (2012) esse contato facilita o debate e o conhecimento sobre as necessidades dos usuários e fortalece o apoio político.

A comissão de seleção, por sua vez, tem o papel importante de assessorar técnica e administrativamente a biblioteca e deve ser composta por membros atuantes e que tenham o poder de decisão quanto à escolha dos itens que serão adquiridos. Para Côrte e Bandeira (2011, p. 61) pode ser formada por "professores, orientador educacional da escola, e o responsável pela biblioteca”, que avaliarão as sugestões encaminhadas pelos alunos, professores e bibliotecários. Esta composição poderá variar, conforme a escola, mas a coordenação desta comissão deve estar a cargo do bibliotecário ou do profissional responsável pela biblioteca. Via de regra a comissão se reúne quando há liberação de verbas (DIAS; PIRES, 2003; WEITZEL, 2006; VERGUEIRO, 2010).

Refletindo sobre a limitação humana de absorver todo o conhecimento publicado atualmente, o desenvolvimento de coleções tornou-se recurso fundamental para se administrarem as coleções de acordo com os interesses e o perfil daqueles que necessitam de informações específicas. Esse processo funciona, portanto, como um filtro do conhecimento registrado, separando o joio do trigo para o uso adequado e exige do bibliotecário e de sua equipe, uma capacidade de análise da informação para selecionar as mais relevantes e 
pertinentes obras produzidas em cada área de interesse e para cada tipo de usuário, explica Weitzel (2002).

Vergueiro (1993) destaca que, de uma maneira geral, o desenvolvimento de coleções irá incluir a avaliação das necessidades dos usuários, a avaliação da coleção atual, a determinação da política de seleção, a coordenação da seleção de itens, o desbastamento e armazenagem de partes da coleção e o planejamento para compartilhamento de recursos. Dessa forma, o desenvolvimento de coleções não é apenas uma simples atividade, mas é um processo de planejamento e de tomada de decisão. Por sua importância, entendeu-se que para a efetivação do processo de desenvolvimento de coleções, seria necessário estabelecer um documento que pudesse legitimar suas etapas nas unidades de informação, servindo de consulta e apoio às tomadas de decisão, estabelecendo-se, assim, as políticas de desenvolvimento de coleções, que, de acordo com Weitzel (2006, p. 18), "é um instrumento importante para desencadear o processo de formação e crescimento de coleções, constituindose num “documento formal elaborado pela equipe responsável pelas atividades".

Cunha e Cavalcanti (2008, p. 285) definem a política de desenvolvimento de coleções, ou política de desenvolvimento de acervos como o "conjunto de critérios, consubstanciados num documento, que tem por objetivo assegurar o crescimento racional e equilibrado de uma determinada coleção ou acervo". Nota-se, portanto, a importância deste documento e a necessidade de sua formalização.

Para Vergueiro (1989, p. 20), as bibliotecas escolares existem, ou pelo menos deveriam existir, "para dar suporte às atividades pedagógicas de suas unidades escolares" e, por esse motivo, mantendo-se integradas ao processo educacional, suas coleções devem seguir os direcionamentos do sistema educacional vigente, pautando-se pelos currículos e bibliografias básicas dos cursos.

Para o autor, a ênfase do processo de desenvolvimento de coleções na biblioteca escolar, estará, portanto, muito mais na seleção de materiais para fins didático-pedagógicos, normalmente alicerçada por uma política de seleção que terá por base o currículo ou programa escolar. As etapas de avaliação e desbastamento serão enfatizadas, nas bibliotecas escolares, à medida que possibilitem adequar a coleção a eventuais mudanças nos programas e/ou currículos. 
Formação e desenvolvimento de acervos em biblioteca escolar como recurso para promover a competência informacional infantil: importância, desafios e perspectivas

Desta forma, no Brasil, de acordo com Campello et al. (2001), a partir das diretrizes dos Parâmetros Curriculares Nacionais, no que diz respeito aos materiais que irão embasar a aprendizagem, observa-se que a característica mais evidente do acervo da biblioteca escolar é a diversidade. Baseada nos "textos de fato" a aprendizagem proposta nos PCN exige uma coleção que contemple a "diversidade de textos que circulam socialmente". Ora, esses textos podem aparecer em suportes variados e, portanto, o acervo da biblioteca deve contemplar essa variedade, oferecendo opções ou selecionando a mais adequada, explicam Campello et al. (2001, p. 84).

De acordo com Abreu (2008) isso significa que crianças e jovens precisam experimentar um contato direto com as fontes de informação que fazem parte do mundo letrado e ter oportunidade de compreender os usos da escrita em diferentes circunstâncias, observando suas várias funções e características. Portanto, uma variedade de textos, gêneros e de suportes deve compor o acervo da biblioteca escolar.

A autora ainda destaca que a coleção da biblioteca escolar deve ser formada em função das propostas curriculares de cada área, oferecendo materiais de consulta dos mais diversos suportes: enciclopédias, atlas, jornais, revistas, dicionários, seja no formato impresso ou no eletrônico.

Nesse sentido, Vergueiro (1989) salienta que a biblioteca escolar é o instrumento para o suporte às atividades pedagógicas e que seu acervo está orientado principalmente no direcionamento do sistema educacional vigente, sendo a seleção baseada no currículo ou no programa escolar. Contudo, sabe-se que selecionar itens direcionados para atender as demandas do currículo escolar é apenas um dos aspectos possíveis. Para que o acervo seja realmente diversificado, não deve ficar somente orientado para isso. É preciso abrir para outras dimensões e necessidades. Por isso, compreender a estrutura para formação de coleções é tão importante, levando-se em consideração também o incentivo à leitura e as atividades de apoio e pesquisa que a biblioteca escolar favorece.

Fragoso (2005) complementa que a biblioteca escolar ideal possui um planejamento de desenvolvimento de coleção, com uma política de seleção e aquisição, que prioriza o projeto de incentivo à leitura, interligados ao quadro pedagógico, e se torna um setor ativo de aprendizagem, com o foco de tornar o indivíduo em um cidadão crítico, participativo e seletivo na sociedade. 
Vergueiro (1993) também ressalta que se deve levar em consideração, as grandes inovações que vêm acontecendo em termos de recursos de informação colocados a serviço das instituições educacionais, que estão transformando as bibliotecas escolares em verdadeiras centrais de multimeios que precisam estar integradas às necessidades da escola.

Aquele modelo de biblioteca centrado no armazenamento para fins de preservação do conhecimento, deu lugar ao "novo modelo baseado no acesso às informações de interesse a partir de estoque ilimitado de conhecimento" (WEITZEL, 2002, p. 64) e isso trouxe consigo possibilidades de inovação nos produtos e serviços oferecidos pelas unidades de informação.

Nesse sentido, Abreu (2008) afirma que a disponibilização da internet nas bibliotecas escolares é importante para garantir material de pesquisa aos trabalhos escolares e Maroto (2009, p. 64) corrobora com Abreu (2008) ao afirmar que as diversificadas fontes de informação e as possibilidades de leitura oferecidas pela biblioteca escolar através de variados suportes, "são condições fundamentais no processo de formação do leitores, de sua interferência crítica e consciente no contexto educacional e social em que vive". Desta forma, a biblioteca escolar, valendo-se das tecnologias atuais de informação, pode oferecer vários recursos para aprimorar, ainda mais, suas atividades na promoção da leitura, utilizando-se, inclusive, de obras disponíveis online, respeitando-se as questões autorais.

Reforçando a importância da diversidade das fontes de informação nos acervos das bibliotecas escolares, também para Perrotti (2008, p. 7), nos dias atuais, cabe à escola promover o contato do aluno com

diferentes suportes, processos e conteúdos culturais e, nesse movimento, ensiná-lo a lidar com as diferentes e múltiplas fontes de conhecimento, escritas, orais, audiovisuais, eletrônicas; ensiná-lo a atribuir valor a cada uma dessas fontes, suas formas, suas linguagens, seus processos; ensinar as possibilidades e os limites que lhes são próprios, seus usos, seus modos de funcionamento.

Ressalta-se, desta forma, as diferentes possibilidades atuais no contexto das fontes de informação. Ainda nessa mesma perspectiva Figueiredo (1991) também reforça que é pelo processo de desenvolvimento de coleções, quando bem executado, que a biblioteca poderá assegurar a qualidade e o tamanho da coleção em concordância com as necessidades informacionais dos usuários.

Mas para que todos esses benefícios apresentados pelos autores sejam efetivados nas bibliotecas escolares, podemos encontrar em Vergueiro (1997) a enumeração de alguns fatores que podem auxiliar os bibliotecários escolares a respeito da formação de uma coleção 
Formação e desenvolvimento de acervos em biblioteca escolar como recurso para promover a competência informacional infantil: importância, desafios e perspectivas

de qualidade. Para o autor a permanência de fontes de informação impressas no acervo deve levar em conta:

a) adequabilidade do livro: o livro é extremamente adequado ao objetivo para o qual foi originalmente criado;

b) custo do livro: é certo que alguns tipos de materiais de informação representam uma opção mais econômica de produção em formato eletrônico;

c) contexto social: entre outras, uma das questões que ainda não está satisfatoriamente equacionada na disseminação via redes eletrônicas diz respeito à confiabilidade da informação.

Além destes fatores, a American Library Association (ALA), apresentou em 1999, alguns critérios específicos que também podem orientar os profissionais envolvidos na etapa de seleção de recursos materiais para as bibliotecas escolares para a formação de coleções adequadas para o ambiente escolar: significado educativo; contribuição que o assunto faz ao currículo e aos interesses dos alunos; comentários favoráveis encontradas em fontes de seleção padrão; recomendações favoráveis com base em pré-visualização e análise de materiais por profissionais; reputação e importância do autor, produtor e editor; validade, moeda, e a adequação do material; contribuição do material à amplitude de pontos de vista representativos sobre questões controversas; alto grau de recurso potencial para o usuário; alta qualidade artística e / ou estilo literário; qualidade e variedade de formato; valor proporcional de custos e / ou necessidade; tempestividade ou permanência e integridade.

É importante ressaltar que na biblioteca escolar, a literatura infanto-juvenil merece destaque e, por isso, como explicam Baptista, Noronha e Cruz (2013), além de assegurar materiais, tempo e espaços destinados à leitura, é primordial que, durante a educação básica, também seja iniciado o trabalho sistemático de letramento literário.

Acredita-se assim, que a observação de tais critérios poderão auxiliar os responsáveis pelos acervos das bibliotecas escolares a também seguirem as recomendações do manifesto da IFLA/UNESCO (1999, p. 2), quando dizem que

o acesso às coleções e aos serviços deve orientar-se pelos preceitos da Declaração Universal dos Direitos do Homem, das Nações Unidas, e não deve estar sujeito a qualquer forma de censura ideológica, política, religiosa ou a pressões comerciais. 
Niliane Cunha de Aguiar e Telma de Carvalho

Diante do exposto, observa-se que o planejamento, a elaboração e a execução de uma política de desenvolvimento de coleções em bibliotecas escolares, possui diversos benefícios, tanto para a organização e gestão da unidade de informação, quanto para o atendimento das necessidades informacionais de seus usuários e de modo especial, para as necessidades informacionais do público infantil, como será apresentado a seguir. 
Formação e desenvolvimento de acervos em biblioteca escolar como recurso para promover a competência informacional infantil: importância, desafios e perspectivas

\section{A relação entre a formação do acervo das bibliotecas escolares e a promoção da competência informacional infantil}

De acordo com Lloyd (2003) tornar-se competente em informação consiste em um processo holístico que sofre influência das relações sociais, físicas e textuais com a informação, as quais demandam uma série de práticas e comprovam a complexidade e a variedade das fontes de informação dentro de um contexto. Diante dessa perspectiva, entendese a importância que a qualidade do acervo possui para a construção da competência informacional do público infantil.

Os autores Johnston e Webber (2006, p. 113) por sua vez, acreditam que a competência informacional consiste na "adoção de um comportamento informacional apropriado para identificar, mediante qualquer canal ou meio, informação adequada às necessidades, levando ao uso correto e ético da informação na sociedade".

Mais uma vez, é possível entender a importante relação entre as necessidades de informação com os materiais adequados para supri-las. E na biblioteca escolar não é diferente, já que o desenvolvimento de uma coleção capaz de formar um acervo de qualidade e variado em relação não apenas aos temas oferecidos, mas também quanto aos diversos gêneros literários assim como em relação aos diversos suportes informacionais atualmente existentes, permite ao usuário uma melhor formação leitora e, consequentemente, um melhor desempenho escolar, especialmente quando este acervo é bem utilizado valendo-se do trabalho colaborativo entre professores e bibliotecários.

Uma das autoras que mais se destaca na perspectiva da competência informacional ligada à aprendizagem é a pesquisadora Carol Collier Kuhlthau. A dimensão da competência informacional no contexto escolar recebeu especial atenção de Kuhlthau, segundo Campello (2006), por acreditar que a formação da competência informacional poderia acontecer através de passos integrados às práticas escolares com o uso eficaz de fontes de informação apropriadas para cada estágio de desenvolvimento escolar da criança.

Outra vertente da compreensão do termo competência informacional, conforme designa Campello (2003), está focado na perspectiva da construção da cidadania, visto que cidadãos competentes no uso da informação possuem melhores condições de tomar decisões relativas à sua responsabilidade social. Em relação às crianças, isso poderá contribuir para que as gerações futuras construam uma sociedade mais consciente, justa e sustentável. 
Com ideia similar, Doherty (2007, p. 6) afirmou que o papel mais importante de uma competência informacional crítica implica em "dar voz àqueles que foram silenciados" e pode ser considerada uma espécie de ativismo que pode instigar os educandos a dar um passo para além de seus paradigmas e a buscar outras vozes. Este ativismo se torna necessário, pois conforme explicam Vitorino e Piantola (2009), as informações disponíveis tendem a ser, mesmo que não deliberadamente, selecionadas e organizadas para favorecer determinados grupos e ideologias. Mais uma vez, observa-se pelo posicionamento dos autores, a importância da qualidade na formação do acervo das bibliotecas escolares.

Também é possível destacar no trabalho de Evans e Saponaro (2005, p. 54) importantes elementos que corroboram com a relação entre a formação e o desenvolvimento de coleções e as necessidades específicas dos usuários. Os autores propõem perguntas que precisam ser realizadas para formar acervos de qualidade, tais como: qual a missão e objetivos da organização? Qual a composição da comunidade que a compõe? Existem grupos específicos a serem atendidos, tais como crianças? Quais os formatos que a biblioteca irá adquirir?

A realização de tais questionamentos, contribuem para a compreensão tanto das realidades de ambiente escolar, quanto das características do público infantil, reforçando a importância que o acervo terá para o leitor e no âmbito da biblioteca escolar.

Atualmente, segundo Campello (2009), o termo designa de forma ampla o conjunto de habilidades necessárias para localizar, interpretar, analisar, sintetizar, avaliar e comunicar informação, seja ela em fontes impressas ou eletrônicas. Já a competência informacional infantil é definida como "a habilidade da criança em lidar (refletir, apropriar, ressignificar) com as informações disponíveis nos mais variados suportes e recursos, apropriadas para a sua faixa etária ou desenvolvimento cognitivo" (AGUIAR, 2018, p. 114).

O bibliotecário escolar, no âmbito da competência informacional infantil, possui um papel primordial, em sua promoção, desenvolvimento e avaliação, pois conforme Dias et al. (2004, p. 2):

[...] os bibliotecários devem ter habilidades especiais em relação ao ensino/aprendizagem da localização de recursos, a formulação adequada das buscas, a decodificação da informação, a localização, a seleção e consulta de registros e de documentos em diferentes suportes e formatos.

Aliado a isso, encontram-se também os valores éticos e legais relativos ao acesso e uso da informação que devem ser apresentados aos alunos pelo bibliotecário. 
Formação e desenvolvimento de acervos em biblioteca escolar como recurso para promover a competência informacional infantil: importância, desafios e perspectivas

Para concluir, se a formação da criança na contemporaneidade passa inevitavelmente pelo contato com as tecnologias da informação e comunicação, entende-se que os segmentos que lidam diretamente com o desenvolvimento da criança precisam se adaptar à era do conhecimento. É inegável que o acesso à informação eletrônica, por parte de crianças, tem crescido muito e, por este motivo, usar essas ferramentas para encontrar a informação desejada é um desafio para esse público, pois "requer um conjunto diferenciado de estratégias de pesquisa e habilidades, mais do que quando se pesquisa nas fontes impressas e está relacionado ao tipo de informação que é desejada" (FIALHO; ANDRADE, 2007, p. 30).

Assim sendo, infere-se que o desenvolvimento e a formação dos acervos das bibliotecas escolares devem ser devidamente planejados para apresentar informações de qualidade, nos mais variados suportes, além de possibilitar o acesso aos recursos tecnológicos que capacitem as crianças não apenas para se tornarem adultos competentes em informação, mas que já favoreçam a autonomia necessária para a formação da competência informacional infantil. É desejável que desde a primeira infância, a criança tenha condições de buscar, apropriar, disseminar e ressignificar as informações que ela precisa para cada etapa de sua evolução cognitiva, intelectual e social.

\section{Considerações finais}

Se a preocupação com o desenvolvimento de coleções em bibliotecas apresenta um nítido incremento a partir das últimas décadas, quando se tornou cada vez mais claro, para bibliotecários e administradores em geral, que era praticamente impossível acompanhar o ritmo alucinante do crescimento dos materiais informacionais, conforme bem explicou Vergueiro (1993), agora, cabe aos responsáveis pelas bibliotecas escolares compreenderem que a elaboração de boa uma política de desenvolvimento de coleções torna a biblioteca "a cara da escola" (ABREU, 2008, p. 32).

Esta premissa responde o questionamento deste estudo e alcança os objetivos almejados, uma vez que, compreende-se que diante das reflexões trazidas pelo diálogo entre os autores da literatura apresentada, é possível concluir que a formação e o desenvolvimento de uma coleção bem planejada, refletida e elaborada dentro de uma política voltada para a qualidade do acervo em consonância com as necessidades da escola e dos alunos, dependerá do trabalho conjunto de professores e bibliotecários que, juntos, poderão desenvolver um 
acervo rico, variado, atraente e afinado com a proposta pedagógica da escola. A participação efetiva do bibliotecário nas instâncias da escola para colaborar com as discussões acerca do planejamento pedagógico e da comissão de seleção, possibilitará ganhos para ambos e, especialmente, para o público atendido.

Por fim, considera-se que um acervo composto pelas premissas da formação e desenvolvimento de coleções favoreça o trabalho do bibliotecário nas ações que envolvam a construção da competência informacional infantil e, quando essa prática for efetivada nas bibliotecas escolares brasileiras, certamente a competência informacional infantil se tornará uma realidade, o que poderá aumentar consideravelmente a qualidade da educação no Brasil.

\section{Referências}

ABREU, Vera Lúcia Furst Gonçalves. A coleção da biblioteca escolar. In: CAMPELLO, B. et al. A biblioteca escolar: temas para uma prática pedagógica. 2. ed. Belo Horizonte: Autêntica, 2008. p. 29-3.

AGUIAR, Niliane Cunha de. O letramento para a competência informacional em bibliotecas escolares: estudo a partir dos projetos políticos pedagógicos dos colégios de aplicação das universidades federais brasileiras. 2018. $271 \mathrm{f}$. Tese (Doutorado em Ciência da Informação) - Universidade Federal de Minas Gerais, Belo Horizonte, 2018. Disponível em: https://repositorio.ufmg.br/bitstream/1843/BUOS-B6PFSK/1/tese_final.pdf. Acesso em: 05 jun. 2021.

AMERICAN LIBRARY ASSOCIATION. Workbook for selection policy writing. Chicago: ALA, 1999. Disponível em:

https://www.ala.org/Template.cfm?Section=dealing\&Template/ContenManagement/Content Display.cfm\&ContentID=11173. Acesso em: 12 jan. 2021.

BARRETO, Cíntia. Biblioteca escolar: ranços e avanços. In: ENCONTRO REGIONAL DE BIBLIOTECAS, 1., 2008, Anais... Araruama: [S.n.], 2008. Disponível em: http://www.educacaopublica.rj.gov.br/biblioteca/educação/0190.html. Acesso em: 09 jan. 2021.

BAPTISTA, Mônica Correia; NORONHA, Amanda de Abreu.; CRUZ, Priscila Maria Caligiorne. Letramento literário na primeira infância. In: COLÓQUIO DE ESTUDOS EM NARRATIVA (CENA), 1., 2013, Uberlândia. Anais do CENA. Uberlândia: UFU, 2013. Disponível em: http://www.ileel.ufu.br/anaisdocena/wpcontent/uploads/2014/02/cena3_artigo_5.pdf. Acesso em: 06 jun. 2021.

BRASIL. Base Nacional Comum Curricular: educação é a base. Brasília: MEC/CONSED/UNDIME, 2017. Disponível em: http://basenacionalcomum.mec.gov.br. Acesso em: 29 ago. 2021. 
Formação e desenvolvimento de acervos em biblioteca escolar como recurso para promover a competência informacional infantil: importância, desafios e perspectivas

BRASIL. Secretaria de Educação Fundamental. Parâmetros curriculares nacionais: introdução aos parâmetros curriculares nacionais. Brasília: MEC/SEF, 1997. 126 p. Disponível em: http://portal.mec.gov.br/seb/arquivos/pdf/livro01.pdf. Acesso em: 04 nov. 2020.

BRASIL. Ministério da Educação. Lei n. ${ }^{\circ} 12.244$ de 24 de maio de 2010: dispõe sobre a universalização das bibliotecas nas instituições de ensino do País. Brasília: Congresso Nacional, 2010. Disponível em: http://www.planalto.gov.br/ccivil_03/_Ato20072010/2010/Lei/L12244.htm. Acesso em: 08 jun. 2021.

CAMPELLO, Bernadete Santos. A escolarização da competência informacional. Revista Brasileira de Biblioteconomia e Documentação: Nova Série, São Paulo, v. 2, n. 2, p. 63-77, dez. 2006. Disponível em: http://www.febab.org.br/rbbd/index.php/rbbd/article/view/18/6. Acesso em: 25 out. 2020.

CAMPELLO, Bernadete Santos. O movimento da competência informacional: uma perspectiva para o letramento informacional. Ciência da Informação, Brasília, v. 32, n. 3, p. 8-37, set./dez. 2003. Disponível em: http://www.scielo.br/pdf/ci/v32n3/19021.pdf. Acesso em: 25 jan. 2021.

CAMPELLO, Bernadete Santos. Letramento informacional no Brasil: práticas educativas de bibliotecários em escolas de ensino básico. 2009. 208 f. Tese (Doutorado em Ciência da Informação) - Universidade Federal de Minas Gerais, Escola de Ciência da Informação, Belo Horizonte, 2009. Disponível em:

http://gebe.eci.ufmg.br/downloads/tese\%20campello\%202009.pdf. Acesso em: 20 out. 2020.

CAMPELLO, Bernadete Santos et al. Apresentação. In: KUHLTHAU, C. Como usar a biblioteca na escola: um programa de atividades para o ensino fundamental. 3. ed. Belo Horizonte: Autêntica, 2009. p.9-12.

CAMPELLO, Bernadete Santos et al. A coleção da biblioteca escolar na perspectiva dos Parâmetros Curriculares Nacionais. Informação \& Informação, Londrina, v. 6, n. 2, p. 71 88, jul./dez. 2001. Disponível em: https://brapci.inf.br/index.php/res/v/34931. Acesso em 08 jun. 2021.

CARIBÉ, Rita de Cássia do Vale. Conspectus: um método para o gerenciamento de coleções em bibliotecas. Revista Digital de Biblioteconomia e Ciência da Informação, Campinas, v. 12, n. 1, p. 39-60, jan./abr. 2014. Disponível em:

https://periodicos.sbu.unicamp.br/ojs/index.php/rdbci/article/view/1617/pdf 53. Acesso em: 01 set. 2021.

CONSELHO FEDERAL DE BIBLIOTECONOMIA; CONSELHO REGIONAL DE

BIBLIOTECONOMIA. Projeto mobilizador: biblioteca escolar: construção de uma rede de Informação para o ensino público. Brasília: CFB/CRB, 2008. Disponível em: https://www.crb10.org.br/legis/PROMOBIL.pdf. Acesso em: 08 jun. 2021.

CÔRTE, Adelaide Ramos; BANDEIRA, Suelena Pinto. Biblioteca escolar. Brasília: Briquet de Lemos, 2011. 176 p. 
Niliane Cunha de Aguiar e Telma de Carvalho

CUNHA, Murilo Bastos da; CAVALCANTI, Cordélia Robalinho de Oliveira. Dicionário de Biblioteconomia e Arquivologia. Brasília: Briquet de Lemos, 2008.

DIAS, Maria Mathilde Kronka et al. Capacitação do bibliotecário como mediador do aprendizado no uso de fontes de informação. Revista Digital de Biblioteconomia e Ciência da Informação, Campinas, v. 2, n. 1, p. 1-16, jul./dez. 2004. Disponível em:

https://periodicos.sbu.unicamp.br/ojs/index.php/rdbci/article/view/2070. Acesso em: 03 jun. 2021.

DIAS, Maria Mathilde Kronka; PIRES, Daniela. Formação e desenvolvimento de coleções de serviços de informação. São Carlos: Ed. UFSCAR, 2003

DOHERTY, John J. Giving voice to the silenced: an essay in support of information literacy. Library Philosophy and Practice, p. 1-8, June 2007. Disponível em:

http://vnweb.hwwilsonweb.com/hww/results/getResults.jhtml?_DARGS=/hww/results/results _com. Acesso em: 3 jun. 2009.

EVANS, G. Edward; SAPONARO, Margaret Zarnosky. Collection development policies. In: EVANS, G. Edward; SAPONARO, Margaret Zarnosky. Developing library and information center collections. 5. ed. Santa Barbara: Libraries Unlimited. 2005. 451 p. Disponível em: https://archive.org/details/developinglibrary00edwa/page/54/mode/2up. Acesso em: 29 ago. 2021.

IFLA. FEDERAÇÃO INTERNACIONAL DE ASSOCIAÇÕES DE BIBLIOTECÁRIOS E INSTITUIÇÕES; UNESCO. ORGANIZAÇÃO DAS NAÇÕES UNIDAS PARA EDUCAÇÃ̃, CIÊNCIA E CULTURA. Manifesto IFLA/UNESCO para biblioteca escolar: a biblioteca escolar no Ensino e aprendizagem para todos. Paris: IFLA/UNESCO, 1999. Disponível em: https://www.ifla.org/files/assets/school-libraries-resourcecenters/publications/school-library-manifesto-pt-brazil.pdf. Acesso em 05 maio 2021.

FIALHO, Janaína Ferreira; ANDRADE, Maria Eugênia Albino. Comportamento informacional de crianças e adolescentes: uma revisão da literatura estrangeira. Ciência da Informação, Brasília, v. 36, n. 1, p. 20-34, jan./abr. 2007. Disponível em: http://www.scielo.br/pdf/ci/v36n1/a02v36n1.pdf. Acesso em: 25 out. 2020.

FIGUEIREDO, Nice Menezes de. Metodologias para promoção do uso da informação: técnicas aplicadas particularmente em bibliotecas universitárias e especializadas. São Paulo: Nobel, 1991.

FONSECA, Edson Nery da. Introdução à biblioteconomia. 2. ed. Brasília: Briquet de Lemos Livros, 2007.

FRAGOSO, Graça Maria. Biblioteca na escola: uma relação a ser construída. Revista ACB: Biblioteconomia em Santa Catarina, Florianópolis, v. 10, n. 2, p. 169-173, jan./ dez., 2005. Disponível em: http://revista.acbsc.org.br/racb/article/view/430/547. Acesso em: 20 maio 2021.

FUNDAÇÃO BIBLIOTECA NACIONAL. Biblioteca pública: princípios e diretrizes. Fundação Biblioteca Nacional, Rio de Janeiro, 2010. Disponível em: 
Formação e desenvolvimento de acervos em biblioteca escolar como recurso para promover a competência informacional infantil: importância, desafios e perspectivas

https://www.bn.gov.br/sites/default/files/documentos/miscelanea/2015/bibliotecapublica_prin cipiosdiretrizes_edicao2.pdf. Acesso em: 08 jun. 2021.

GARCEZ, Eliane Fioravante. O bibliotecário nas escolas: uma necessidade. Revista ACB: Biblioteconomia em Santa Catarina, Florianópolis, v. 12, n. 1, p.27-41, 2007. Disponível em: https://revista.acbsc.org.br/racb/article/view/492/633. Acesso em: 06 maio 2021.

HAUM, Haieska (org.). Política de desenvolvimento de acervo das bibliotecas escolares da Rede Municipal de Educação de Belo Horizonte. Belo Horizonte: PBH/SME, 2009. 32 p. Disponível em:

https://issuu.com/coordenadoriadoprogramadebiblioteca/docs/pdabe_rmebh_final_novembro. Acesso em: 07 jun. 2021.

JOHNSTON, Bill; WEBBER, Sheila. As we may think: information literacy as a discipline for the information age. Research Strategies, v. 20, n. 3, p. 108-121, 2006. Disponível em: http://www.sciencedirect.com/science? ob=ArticleListURL\&_method=lis_ArticleListID=890 4746. Acesso em: 10 dez. 2011.

LLOYD, Annemaree. Information literacy: the meta-competency of the knowledge economy? An exploration paper. Journal of Librarianship and Information Science, v. 35, n. 2, Jun. 2003. p. 87-92. Disponível em: http://lis.sagepub.com/cgi/reprint/35/2/87. Acesso em: 03 jan. 2012.

MAROTO, Lúcia Helena. Biblioteca escolar, eis a questão!: do espaço do castigo ao centro do fazer educativo. Belo Horizonte: Autêntica, 2009.

MARTÍNEZ-SILVEIRA, Martha; ODDONE, Nanci. Necessidades e comportamento informacional: conceituação e modelos. Ciência da Informação, Brasília, v. 36, n. 1, p. 118127, maio/ago. 2007. Disponível em: http://www.scielo.br/pdf/ci/v36n2/12.pdf. Acesso em: 03 ago. 2020.

PAIVA, Jane; BERENBLUM, Andréa. Programa Nacional de Biblioteca da Escola (PNBE): uma avaliação diagnóstica. Pro-Posições, Campinas, v. 20, n. 1, p. 173-188, jan./abr. 2009. Disponível em http://www.scielo.br/pdf/pp/v20n1/v20n1a10.pdf. Acesso em: 12 jan. 2021.

PERROTI, Edmir. Proposta pedagógica: a aventura de conhecer. Salto para o Futuro, Brasília, v. 18, n. 15, set. 2008. Disponível em:

http://www2.eca.usp.br/nucleos/colabori/documentos/PERROTTI_\%20A\%20aventura\%20de \%20conhecer.pdf. Acesso em: 02 maio 2020.

PIERUCCINI, Ivete. A ordem informacional dialógica: estudo sobre a busca de informação em educação. Tese (Doutorado em Ciência da Informação e Documentação) - Universidade de São Paulo, Escola de Comunicação e Artes, São Paulo, 2004. Disponível em: http://www.teses.usp.br/teses/disponiveis/27/27143/tde-14032005-144512. Acesso em: 12 jan. 2021.

SILVA, Edna Lúcia da; MENEZES, Estera Muszkat. Metodologia da pesquisa e elaboração de dissertação. 4. ed. Florianópolis: UFSC, 2005. 138p. 
Niliane Cunha de Aguiar e Telma de Carvalho

SILVA, Larissa da Costa e. Diretrizes para a política de desenvolvimento de coleções nas bibliotecas escolares. Monografia (Bacharelado em Biblioteconomia) - Universidade de Brasília - Brasília: UNB, 2011. 72 f. Disponível em:

https://bdm.unb.br/bitstream/10483/2980/1/2011_LarissadaCostaeSilva.pdf. Acesso em: 12 maio 2021.

TAQUETTE, Stella R.; BORGES, Luciana. Pesquisa qualitativa para todos. Petrópolis: Vozes, 2020. 206 p.

VERGUEIRO, Waldomiro. Desenvolvimento de coleções. São Paulo: Polis, 1989.

VERGUEIRO, Waldomiro. Desenvolvimento de coleções: uma nova visão para o planejamento de recursos informacionais. Ciência da Informação, Brasília, v. 22, n. 1, p. 1321, jan./abr. 1993. Disponível em: http://revista.ibict.br/ciinf/article/view/512. Acesso em 08 jun. 2021.

VERGUEIRO, Waldomiro. O futuro das bibliotecas e o desenvolvimento de coleções: perspectivas de atuação para uma realidade em efervescência. Perspectivas em Ciência da Informação, Belo Horizonte, v. 2, n. 1, p. 93-107, jan./jun. 1997. Disponível em: http://portaldeperiodicos.eci.ufmg.br/index.php/pci/article/view/629. Acesso em: 09 jun. 2021.

VERGUEIRO, Waldomiro. Seleção de materiais de informação. 3.ed. Brasília: Briquet de Lemos, 2010. 120 p.

VITORINO, Elizete Vieira; PIANTOLA, Daniela. Competência informacional, bases históricas e conceituais: construindo significados. Ciência da Informação, Brasília, v. 38, n. 3, p. 130-141, set./dez., 2009. Disponível em:

http://revista.ibict.br/ciinf/index.php/ciinf/article/view/1745/1343. Acesso em: 11 out. 2020..

WEITZEL, Simone da Rocha. O desenvolvimento de coleções e a organização do conhecimento: suas origens e desafios. Perspectivas em Ciência da Informação, Belo Horizonte, v. 7, n. 1, p. 61 - 67, jan./jun. 2002. Disponível em:

http://portaldeperiodicos.eci.ufmg.br/index.php/pci/article/view/414. Acesso em: 09 jun. 2021.

WEITZEL, Simone da Rocha. Desenvolvimento de coleções: origem dos fundamentos contemporâneos. Transinformação, Campinas, v. 24, n. 3, p. 179-190, set./dez., 2012.

WEITZEL, Simone da Rocha. Elaboração de uma política de desenvolvimento de coleções em bibliotecas universitárias. Rio de Janeiro: Interciência; Niterói: Intertexto, 2006. 